\title{
SOBRE LA TRADUCCIÓN DE TÉRMINOS AGRÍCOLAS DEL FRANCÉS AL ESPAÑOL: ESTUDIO DE CASO \\ Enriqueta Tijeras López. \\ Universidad de Murcia
}

\begin{abstract}
This paper constitutes the parcial result of a terminological and translatological research conducted at the General Linguistics and Literature Theory Department of the University of Granada focusing on the problems posed by specialized terminology of agriculture within the French-Spanish language combination. To be more specific, this study is focused on the bilingual terminology of potato, extracted from a specialized corpus in French and Spanish published in France in 2004.
\end{abstract}

KEYWORDS: scientific and technical translation (French-Spanish), agricultural terminology (French-Spanish), didactics of scientific and technical translation (French-Spanish).

\section{RESUMEN}

Este artículo que aquí presentamos es el resultado parcial de una investigación terminológica y traductológica llevada a cabo en el Departamento de Lingüística General y Teoría de la Literatura de la Universidad de Granada sobre la problemática de traducción que presenta la terminología especializada de la Agricultura dentro de la combinación lingüística francés-español. En concreto, este estudio se basa en la terminología bilingüe de la patata, extraída de un corpus especializado en francés y en español, publicado en Francia en 2004.

PALABRAS CLAVE: traducción científico-técnica (francés-español), terminología agrícola (francés-español), didáctica de la traducción científicotécnica (francés-español. 
1. INTRODUCCIÓN: ESTADO DE LA CUESTIÓN Y LITERATURA DISPONIBLE SOBRE TRADUCCIÓN CIENTÍFICO-TÉCNICA (FRANCÉS-ESPAÑOL)

Del análisis de las fuentes disponibles sobre el ámbito de la traducción científico-técnica, dentro de la combinación francés-español, hemos extraído las siguientes conclusiones:

1. El estudio de la terminología y de la traducción científico-técnica en general, y atendiendo a la combinación lingüística francés-español en particular, se centra, ante todo, en dos grandes ámbitos: el ámbito biosanitario y el relacionado con las nuevas tecnologías y la informática.

2. Son escasos los trabajos que inciden sobre la problemática de la traducción científico-técnica dentro del ámbito agrícola y, menos aún, dentro de la combinación lingüística francés-español.

3. La mayoría de la literatura existente incide sobre la combinación lingüística inglés-español. Esto se explica si tenemos en cuenta la condición del inglés como lingua franca de la comunicación científico-técnica a escala internacional y la importancia del mercado profesional de la traducción científico-técnica dentro de la combinación lingüística inglés-español.

4. Los trabajos sobre terminología agrícola se centran, sobre todo, en el establecimiento de equivalentes multilingües que aparecen recogidos en glosarios y diccionarios elaborados en el seno de instituciones internacionales (CEE, UE, FAO, etc.).

5. Son escasos los diccionarios especializados disponibles, dentro de la combinación lingüística francés-español, que inciden exclusivamente en la combinación lingüística francés-español.

6. Son numerosos, sin embargo, los diccionarios monolingües (en francés o en español) y multilingües (que incluyen el francés o el español) que incluyen terminología agrícola dentro de un abanico más amplio de disciplinas, más o menos relacionadas: industria, botánica, ciencias naturales, etc.

7. Son numerosas también las obras que, aunque se centren en otros ámbitos científicos, establecen parámetros de definición del trabajo terminológico. 
8. Son casi inexistentes los trabajos de investigación (tesis doctorales) que inciden sobre la problemática de la traducción de documentos agrícolas.

Este estado de la cuestión justifica la puesta en marcha del trabajo de investigación citado más arriba, que vio la luz finalmente como tesis doctoral, presentada por la autora de este artículo, el pasado 13 de diciembre de 2008 en el Departamento de Lingüística General y Teoría de la Literatura de la Universidad de Granada con el título: La traducción de términos especializados de Agricultura. Aplicaciones a la didáctica y a la práctica profesional de la traducción científicotécnica del francés al español (publicación electrónica disponible en la web de la Universidad de Granada, www.ugr.es).

\section{EL DISEÑO DEL TRABAJO DE CAMPO TERMINOLÓGICO}

Una vez detectadas las carencias de investigación en el ámbito de la traducción de textos de Agricultura, dentro de la combinación francés-español, decidimos abordar este proyecto delimitando un campo objeto de estudio: la dimensión terminológica en los textos de Agricultura que versan sobre la patata, su cultivo y sus enfermedades.

La metodología empleada en el diseño del trabajo de campo se resume como sigue:

1. Hemos limitado nuestra investigación a dos catálogos sobre la patata (uno en español y otro en francés), editados por empresas francesas del sector en el año 2005, de los que hemos extraído una serie de fichas terminológicas (términos principales) con sus correspondientes subentradas relativas a enfermedades que pueden afectar a cada tipo de patata.

2. Estos catálogos han constituido el corpus de referencia para extraer la terminología que se ha tratado en el trabajo realizado.

3. Hemos seleccionado los términos relacionados, para cada tipo de patatas, con las enfermedades que pueden afectar a cada una de ellas.

4. Hemos dividido la base de datos por términos principales (cada tipo de patata) y subentradas relacionadas (enfermedades que pueden afectar a cada tipo de patata).

5. Hemos introducido una definición, extraída de diversas fuentes documentales, fundamentalmente electrónicas, para cada enfermedad. 
6. A modo de introducción del término principal, hemos incluido, de forma sistemática, toda una serie de datos identificativos de la patata en cuestión.

7. Por último, una vez establecido el corpus terminológico y completados los diversos apartados de cada una de las fichas, hemos procedido a la realización de un análisis traductológico y terminológico del corpus, entendido como un todo.

\subsection{El MODELO DE FICHA TERMINOLÓGICA}

El modelo de ficha terminológica utilizado en este trabajo de investigación comprende los siguientes apartados:

1. Se reconoce cada ficha por su término principal y las subentradas relacionadas (enfermedades que afectan a ese tipo específico de patata).

2. En todos los casos se recoge, para el término principal, el nombre, la procedencia, la categoría y la madurez que presenta.

3. A continuación se recogen las enfermedades más frecuentes, en francés y en español, la definición, los síntomas que la acompañan y el agente que produce la enfermedad.

4. Por último, se recogen las fuentes documentales que han servido de referencia para incluir todos los datos que se recogen en la ficha.

EJEMPLO:

\section{FICHA No 1}

\begin{tabular}{|l|l|}
\hline Término principal (francés) & Término principal (español) \\
ADRIANA & ADRIANA \\
Procedencia: Station de Recherche du & Procedencia: Station de Recherche du \\
Comité Nord-France & Comité Nord-France \\
Categoría: consommation & Categoría: consumo \\
Madurez: demi-précoce & Madurez: semitemprana \\
\hline
\end{tabular}




\section{Enfermedades a las que está expuesta la patata}

\section{Fr. MILDIOU DU TUBERCULE Esp. MILDIU Del TUBÉRCULO}

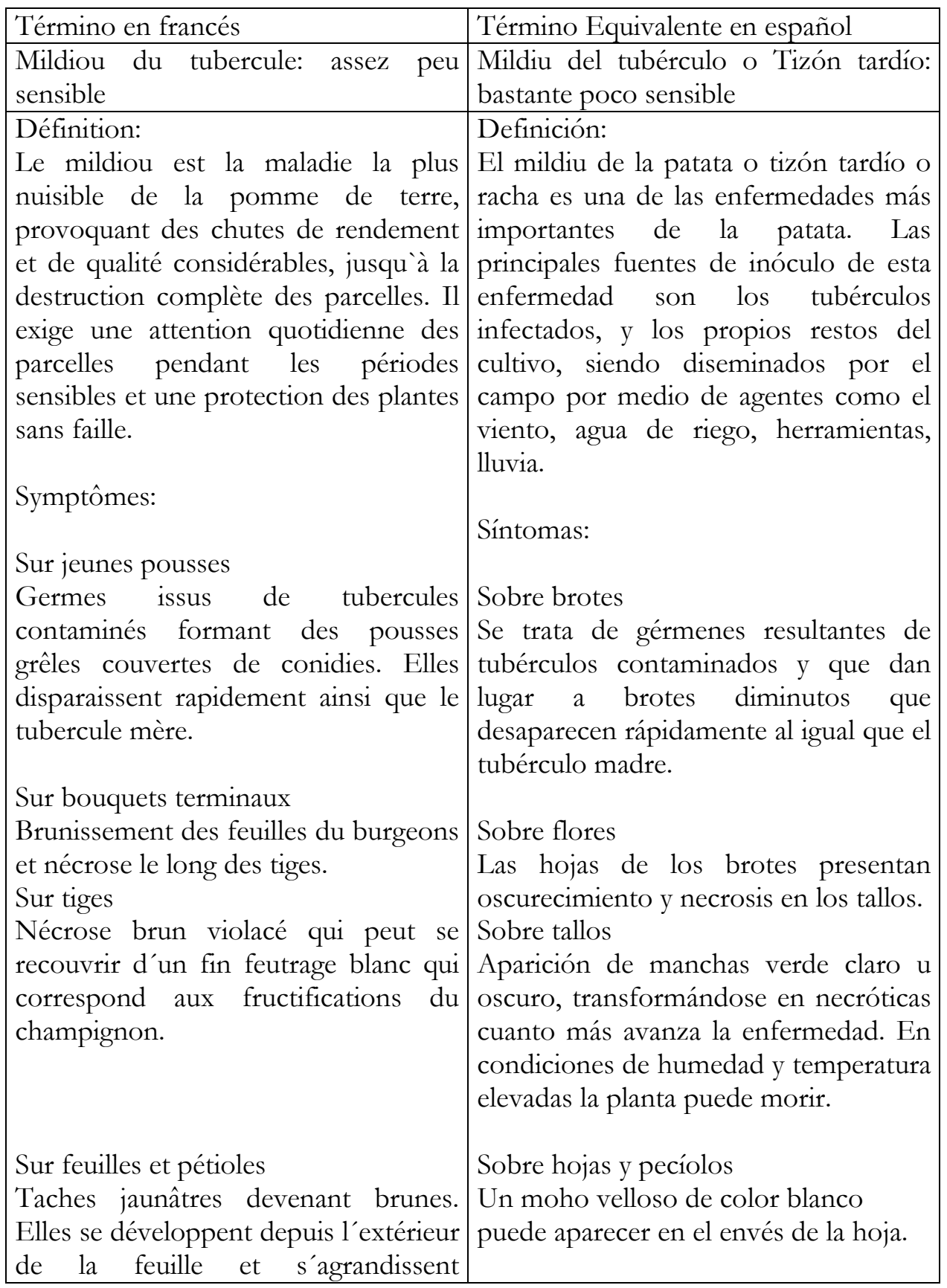




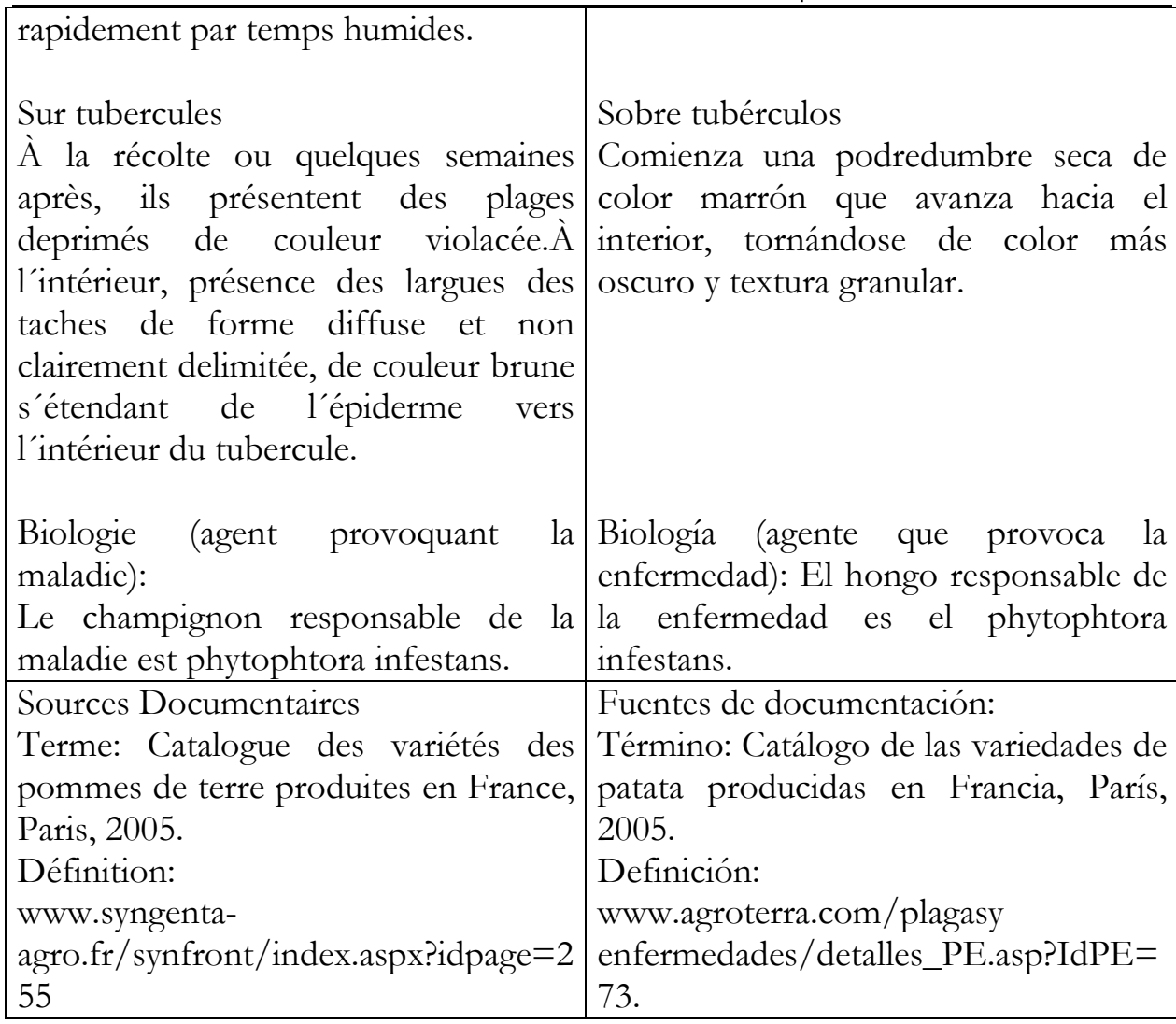

3. RESULTADOS DE LA INVESTIGACIÓN: GLOSARIO DE TÉRMINOS RELACIONADOS CON LAS ENFERMEDADES DE LA PATATA (FRANCÉS-ESPAÑOL)

Del estudio pormenorizado de la terminología extraída de los documentos de referencia (en francés y en español), se llegó a establecer toda una serie de glosarios bilingües relacionados con los tipos de patata, sus cultivos, las formas de tratamiento y las enfermedades.

En este caso recogemos los resultados obtenidos en relación con la terminología que describe las enfermedades a las que puede estar expuesta la patata.

Términos en Francés

\begin{tabular}{|l|l|}
\hline 1. Affaiblissement & Debilitamiento \\
\hline 2. Attaques & Ataques, afectaciones \\
\hline
\end{tabular}


ENTREC ULTURAS Número 1. ISSN: 1989-5097. Fecha de publicación: 27-03-2009

\begin{tabular}{|l|l|}
\hline 3. Bactérie & Bacteria \\
\hline 4. Bigarrure & Abigarramiento, Mezcla \\
\hline 5. Brunissement & Oscurecimiento, Pardeamiento \\
\hline 6. Coeur creux & Corazón hueco \\
\hline 7. Champignon & Hongo \\
\hline - vasculaire & - vascular \\
\hline 8. Changres & Chancros \\
\hline 9. Chutes & Caída \\
\hline Chutes des feuilles & Caída de hojas \\
\hline $\begin{array}{l}\text { 10. Décoloration } \\
\text { Étiolement }\end{array}$ & Decoloración \\
\hline $\begin{array}{l}\text { 11. Défeuillaison } \\
\text { Défoliation }\end{array}$ & Deshoje \\
\hline 12. Déformation & \\
\hline - foliaire & Deformación \\
\hline 13. Dessèchement & - foliar \\
\hline 14. Doryphore & Retorcimiento, Agostamiento, \\
\hline 15. Éffeuillage & Desecación \\
\hline 16. Éffeuillaison & Escarabajo de la patata \\
\hline 17. Éffeuiller & Deshoje, Deshojadura, \\
\hline 18. Égermage & Caída de la hoja \\
\hline 19. Enkystée, forme & Deshoje, Defoliación \\
\hline 20. Enroulement (PLRV) & Deshojar \\
\hline 21. Enroulement des feuilles & Desbrotado \\
\hline 22. Faner & Enquistada, forma \\
\hline 23. Fané & Enrollado (PLRV) \\
\hline 24. Feuilles avec un toucher craquant & Enrollamiento de las hojas \\
\hline $\begin{array}{l}\text { 25. Flétrissement } \\
\text { Détrissure }\end{array}$ & Marchitarse \\
\hline 26. Foliole & Marchito con aspecto crujiente \\
\hline - filiforme & Marchitamiento \\
\hline - déformé & Susariosis \\
\hline - bosselé & Foliolo \\
\hline - enroulé & - filiforme \\
\hline - courbé & - deformado \\
\hline - chlorotique & - abollonado \\
\hline 27. Formation de crevasses & - enrollado \\
\hline 28. Frisolée & - chcorvado \\
\hline 29. Fusariose & \\
\hline 30. Gale & Agrietamiento \\
\hline
\end{tabular}


ENTREC ULTURAS Número 1. ISSN: 1989-5097. Fecha de publicación: 27-03-2009

\begin{tabular}{|c|c|}
\hline - commune & - común \\
\hline - commune en relief & - profunda protuberante \\
\hline - commune en pustules & - cóncava protuberante \\
\hline - plate ou superficielle & - superficial \\
\hline - en liège & - reticular \\
\hline $\begin{array}{l}\text { - verruqueuse } \\
\text { - noire }\end{array}$ & - Verrugosa \\
\hline 31. Germes & Gérmenes \\
\hline 32. Infection & Infección \\
\hline 33. Jaunissement & Palidez, Amarilleo \\
\hline 34. Maladie & Enfermedad \\
\hline - bactérienne & - bacteriana \\
\hline - infectieuse & - infecciosa \\
\hline - parasitose & - parasitaria \\
\hline 35. Mildiou & Mildiu \\
\hline - du feuillage & - (Mildeu) del follaje \\
\hline - du Tubercule & - (Mildeu) del tubérculo, Tizón Tardío \\
\hline 36. Mosaique & Mosaico \\
\hline - à large plages claires & - suave \\
\hline 37. Nanisme & Enanismo \\
\hline $\begin{array}{l}\text { 38. Nécrose } \\
\text { Nervation }\end{array}$ & $\begin{array}{l}\text { Necrosis } \\
\text { Podredumbre }\end{array}$ \\
\hline - nervaire & - foliar \\
\hline - internervaire & - interfoliar \\
\hline 39. Nématode & Nematodo \\
\hline - à Kyste R0 1-4 & - del quiste R0 1-4 \\
\hline - doré (de la pomme de terre) & - dorado de la patata \\
\hline 40. Noircir & Pudrirse, Ennegrecerse \\
\hline 41. Noircissement & Pardeamiento, Pardeado \\
\hline 42. Nuisibilité & Nocividad \\
\hline 43. Nuisible & Perjudicial, Nocivo \\
\hline 44. Parasite & Parásito \\
\hline 45. Pathogène & Patógeno \\
\hline 46. Perte & Pérdida \\
\hline 47. Plages & Manchas \\
\hline 48. Pourriture & Podredumbre \\
\hline 49. Puceron & Pulgón, áfido \\
\hline 50. Putréfaction & Putrefacción, pudrición \\
\hline 51. Rougissant & Enrojecido \\
\hline 52. Rouille & Enrojecimiento, \\
\hline - des feuilles & - de las hojas \\
\hline 53. Rugosité & Rugosidad \\
\hline
\end{tabular}


ENTREC ULTURAS Número 1. ISSN: 1989-5097. Fecha de publicación: 27-03-2009

\begin{tabular}{|l|l|}
\hline 54. Symptome & Síntoma \\
\hline 55. Tache & Mancha \\
\hline - cendrées & - negras internas \\
\hline - de rouille & - marrones \\
\hline - foliaire & - foliar \\
\hline - jaune & - amarilla \\
\hline - réticulaire & - reticular \\
\hline 56. Tumeur & Tumor \\
\hline 57. Verrue & Verrugas \\
\hline 58. Ver & Gusano \\
\hline 59. Virus & Virus \\
\hline - A & - A \\
\hline - X & $-\mathrm{X}$ \\
\hline- Y & $-\mathrm{Y}$ \\
\hline
\end{tabular}

\section{A MODO DE CONCLUSIÓN}

Este trabajo que aquí presentamos pretende ilustrar la investigación llevada a cabo, de forma más extensa, en el Departamento de Lingüística General y Teoría de la Literatura de la Universidad de Granada.

El glosario resultante sobre enfermedades que afectan a la patata constituye uno de los resultados obtenidos con la investigación llevada a cabo en torno a la terminología de la patata en francés y en español.

Las conclusiones nos acercan a lo que ocurre en otros ámbitos de la traducción científico-técnica. Por un lado existen términos que son sumamente técnicos y que no se utilizan fuera del ámbito del estudio de las patologías que puedan afectar a las patatas. Hay otros casos en los que los términos pertenecen a la lengua común y se utilizan en contextos agrícolas para describir afecciones de la patata.

\section{BIBLIOGRAFÍA DE REFERENCIA}

\subsection{CATÁLOGOS SOBRE LA PATATA}

FNPPT-ARVALIS-ITPT (juillet 2004): Catalogue des varietés de pommes de terre produites en France. París, Éditions du Carrousel. ISBN: 2-910904-04-0.

FNPPT-ARVALIS-ITPT (julio 2004): Catálogo de las variedades de patata producidas en Francia. París, Éditions du Carrousel. ISBN: 2-910904-04-0 [traducción al español de Moisés Ponce de León y Anne Ponce de León]. 


\subsection{OBRAS DE REFERENCIA EN ESPAÑOL}

Bender, A. E. (1994): Diccionario de nutrición y tecnología de los alimentos. Zaragoza, Acribia [trad. de B. Sanz Pérez].

Carrascosa SÁnchez, J. (1985): Diccionario de alimentos y servicios "El Universal'. Torrejón de Ardoz, P- Ibáñez.

VV. AA. (1987): Diccionario de agricultura. Madrid, Mundi Prensa.

\subsection{OBRAS DE REFERENCIA EN FRANCÉS-ESPAÑOL}

Grijalba Castaños, C. (2000): Diccionario de agricultura y ciencias afines. Francésespañol/español-francés. Almería, Universidad de Almería.

LÓpez SAntiago, M. (2005): Estudio del léxico francés de la agricultura ecológica. Terminología, neología y traducción al español. Valencia, Universidad de Valencia.

PRessat, R. (1987): Diccionario de demografía: completado con un indice temático y vocabularios castellano-francés y francés-castellano. Barcelona, Oikos-Tau.

\subsection{DiCCIONARIOS MULTILINGÜES QUE INCLUYEN TERMINOLOGÍA AGRÍCOLA}

Cemagref (1990): Dictionnaire technologique (vol. 8). Machinisme et equipements agricoles (français-english, deutsch, español, italiano, portugués). París, La Maison du Dictionnaire.

CONSEIL INTERNATIONAL DE LA LANGUE FRANÇAISE (1999): Dictionnaire d'agriculture trilingue (français-anglais-allemand). Conseil International de la Langue Française.

ESCARPIT (1995) Eurolexique: la vigne et le vin (français-anglais-espagnol-allemanditalien-portugais). Burdeos, Presses Universitaires de Bordeaux.

FAO. (1979): Agrarian Reform and Rural Development / Réforme agraire et développement rural / Reforma agraria y desarrollo rural. Roma, FAO. Idiomas: Inglés, francés, español.

- (1979): Milk and Milk Products: Terminology / Terminologie du lait et des produits laitiers / Terminología de la leche. Roma, FAO. Idiomas: inglés, francés, español.

- (1979): Rice Terminology / Terminologie du riz. / Terminología del arroz. Roma, FAO. Idiomas: inglés, francés, español, árabe.

- (1979): Términos de medio ambiente relacionados con la agricultura / Terms on Environment Related to Agriculture. Roma, FAO. Idiomas: español, inglés, francés, árabe. 
- (1981): Términos de piscicultura / Selected Terms in Fish Culture / Choix de termes de pisciculture. Roma, FAO. Idiomas: español, inglés, francés, árabe.

- (1983): Plantas y productos vegetales de importancia económica / Plants and Plant Products of Economic Importante. Roma, FAO. Idiomas: español, inglés, latín, francés, alemán.

GOUADEC, D. (dir.) (1992). Dictionnaire automatique quadrilingue de l'agroalimentaire. Rennes, Université de Rennes 2-Haute Bretagne.

Haensch, G. y Haberkamp De Anton, G. (1995): Dictionary of Agriculture: German-English-French-Spanish-Russian. Ámsterdam, Elsevier.

Merino Rodríguez, M. (comp.) (1966): Lexicon of Plant Pests and Diseases. Ámsterdam, Elsevier. Idiomas: latín, inglés, francés, español, italiano, alemán.

TERMESP (1994): Alimentos: diccionario cientifico y técnológico español-inglés-alemánfrancés. Madrid, Centro de Información y Documentación Científica. 